\title{
A Biodegradable Slotted Tube Stent Based on Poly(L-lactide) and Poly(4-hydroxybutyrate) for Rapid Balloon-Expansion
}

\author{
Niels Grabow, ${ }^{1}$ Carsten M. Bünger, ${ }^{2}$ Christine Schultze, ${ }^{1}$ Kathleen Schmohl, ${ }^{1}$ David P. Martin, ${ }^{3}$ \\ Simon F. Williams, ${ }^{3}$ Katrin Sternberg, ${ }^{1}$ and Klaus-Peter Schmitz ${ }^{1}$ \\ ${ }^{1}$ Institute for Biomedical Engineering, University of Rostock, Ernst-Heydemann-Str. 6, D-18057 Rostock, Germany; \\ ${ }^{2}$ Department of Surgery, University of Rostock, Schillingallee 35, D-18057 Rostock, Germany; and ${ }^{3}$ Tepha, Inc., 99 Hayden \\ Avenue, Suite 360, Lexington, MA 02421, USA
}

(Received 30 March 2007; accepted 21 August 2007; published online 11 September 2007)

\begin{abstract}
Safe vascular stent application requires rapid expansion of the stent to minimize the risk of procedural ischemia. While high expansion speeds can be achieved with metallic stents, they are not necessarily feasible with biodegradable polymeric stents due to the viscoelastic material behavior. This study reports on a novel biodegradable polymer blend material based on poly(L-lactide) (PLLA) and poly(4-hydroxybutyrate) (P4HB), and describes the mechanical properties and in vitro degradation behavior of a balloon-expandable slotted tube stent concept. The stent prototypes with nominal dimensions of $6.0 \times 25 \mathrm{~mm}$ were manufactured by laser machining of solution cast PLLA/ P4HB tubes (I.D. $=2.8 \mathrm{~mm}, d=300 \mu \mathrm{m})$. The stents were expanded within 1 min by balloon inflation to 8 bar, after 5 min preconditioning in $37^{\circ} \mathrm{C}$ water. Recoil and collapse pressure were $4.2 \%$ and 1.1 bar, respectively. During in vitro degradation collapse pressure initially increased to a maximum at $4 \mathrm{w}$ and then decreased thereafter. After $48 \mathrm{w}$, molecular weight was decreased by $82 \%$. In summary, the PLLA/P4HB slotted tube stents allowed for rapid balloonexpansion and exhibited adequate mechanical scaffolding properties suitable for a broad range of vascular and nonvascular applications.
\end{abstract}

Keywords-PLLA, P4HB, Recoil, Collapse, Laser machining, Mechanical properties, Degradation.

\section{INTRODUCTION}

Biodegradable polymer stents are currently being revisited as a solution to the adverse potential for delayed endothelialization and late thrombosis recently documented for first generation drug-eluting stents. ${ }^{12,15}$ While still providing mechanical support to prevent recoil and restenosis, biodegradable alternatives may

\footnotetext{
Address correspondence to Niels Grabow, Institute for Biomedical Engineering, University of Rostock, Ernst-HeydemannStr. 6, D-18057 Rostock, Germany. Electronic mail: niels.grabow@ medizin.uni-rostock.de
}

also provide additional benefits, such as compatibility with noninvasive imaging technologies, stented segments suitable for future surgical revascularization, as well as positive remodeling and a physiological response to pulsatile blood flow. ${ }^{6,29}$

The purpose of this study was to develop a biodegradable polymer stent with high expansion speed, since quick delivery of intravascular stent systems is an important safety factor largely contributing to the success of vascular interventions. In particular coronary interventions require rapid balloon expansion protocols to avoid the risk of myocardial infarction or other adverse cardiac events. ${ }^{1}$ Similar requirements must be met in peripheral interventions, such as in carotid or neurovascular procedures, where rapid stent expansion is also required to prevent stroke, minimize ischemia, and to ensure immediate vascular scaffolding.

While high stent expansion speeds are part of everyday clinical practice with currently used metallic stents, both self-expanding and balloon-expandable, they are not necessarily feasible with biodegradable polymeric stents due to their viscoelastic material behavior.

In general, major challenges in the development process of polymeric stent concepts are being encountered in: (i) the selection of appropriate structural polymer materials, which must be biodegradable and biocompatible at the same time, (ii) the development of a stent design adapted to the polymeric material properties, and (iii) the identification of a stent expansion protocol adapted to the intended application site.

Practically, it is an immanent problem of polymeric materials, that their structural properties are inferior to those of metals. For this reason, the design of a polymeric stents with similar mechanical properties, such as low recoil and high radial strength, will require greater 
strut dimensions. To keep strut thickness as low as possible, polymeric stent designs will need to be highly optimized towards the polymeric material properties to take most advantage of them. Furthermore, polymeric stent deliverability may be restricted, for instance due to higher profile and longer expansion time, which may require modified delivery devices and predilation of target lesions.

Due to these hindrances only a small number of different biodegradable polymeric stent concepts have so far been investigated in clinical trials as an alternative to permanent stents. In 2000, Tamai et al., described the first clinical application of a self-expanding PLLA zig-zag fiber stent, which can be expanded in 0.5 min with a balloon catheter heated to $50{ }^{\circ} \mathrm{C}$ and inflated to $6-14 \mathrm{~atm} .^{23}$ A peripheral size version of this stent is being investigated in the PERSEUS clinical trials. $^{2}$

Currently, the everolimus-eluting BVS stent (Abbott Vascular, Santa Clara, USA), a coronary polymer stent based on PLLA, is being investigated in the ABSORB clinical trial. ${ }^{19}$ Recent data on the in vivo performance of this stent, which has a strut thickness of $150 \mu \mathrm{m}$ at a nominal diameter of $3.0 \mathrm{~mm}$, is very promising and demonstrates an acute recoil comparable to a metallic stent. ${ }^{25}$

A larger number of groups have already demonstrated the high potential of their technology in the experimental stage. Lauto et al., have reported on experimental work on a self-expanding chitosan helical coil stent, fully expanding within 3 min. ${ }^{16}$ In a similar design approach, Vogt et al., developed a balloonexpandable helical coil stent from poly(D,L-lactide) (PDLLA), capable of being expanded in $1 \mathrm{~min}$ with balloon pressures of 10-12 atm. ${ }^{28}$ Venkatraman et al., are also pursuing another similar design approach using a self-expanding elastic memory helical coil stent based on PLLA and poly(L-lactide-co-glycolide) (PLGA), which self-expands in a few minutes. ${ }^{27} \mathrm{Su}$ et al., have described a balloon-expandable fiber stent based on PLLA, which can be expanded in $1.5 \mathrm{~min}$ with balloon inflation to 10 bar. $^{22}$ Not disclosing their exact expansion protocol, Uurto et al., have reported on their animal experience with a self-expanding fiber stent based on PDLLA, which is dilated with a balloon to support self-expansion. ${ }^{26}$ In the non-vascular field, Isotalo et al., have clinically investigated self-expanding urethral PLLA stents. ${ }^{14}$ Properties of this stent have recently been improved by changing the original spiral design $(0.7 \mathrm{~mm}$ wire) to a braided mesh $(0.35 \mathrm{~mm}$ wire $) .{ }^{13}$

In contrast to the above mentioned fiber or coil based self-expanding or balloon-expandable polymer stent concepts, our group is pursuing the development of a balloon-expandable slotted tube stent concept.
While drug incorporation may be equally challenging, and self-expanding fiber stents may be safer in applications vulnerable to external mechanical impact, balloon-expandable slotted-tube concepts may be particularly advantageous where precise sizing and high radial strength are desired.

We have reported earlier on a PLLA stent that requires expansion over $8 \mathrm{~min}$, which was successfully applied in a surgical anastomosis model in the porcine A. iliaca with a follow-up of 6 weeks. ${ }^{4,8}$

The present study describes in detail the mechanical properties and in vitro degradation of peripheral size $(6.0 \times 25 \mathrm{~mm})$ slotted tube stents made of a novel PLLA/P4HB blend material, developed and fabricated by our group, that allow for rapid balloon-expansion.

\section{MATERIALS AND METHODS}

\section{Polymer Materials and Stent Prototype Manufacture}

The stents were manufactured from a polymer blend material of high molecular weight PLLA (Resomer ${ }^{\circledR}$ L214, Boehringer Ingelheim Pharma, Ingelheim, Germany) and P4HB (TephaFLEX ${ }^{\circledR}$, Tepha, Inc., Cambridge, MA, USA), with a mass ratio of $78 / 22 \%$. The novel blend component $\mathrm{P} 4 \mathrm{HB}$ is a thermoplastic biopolymer produced in a recombinant fermentation process using $E$. coli $\mathrm{K} 12$. Its degradation product $4 \mathrm{HB}$ is a natural human metabolite present in several organs. P4HB is currently evaluated for a number of medical applications. ${ }^{17}$

In a first step, a $1.6 \%(\mathrm{w} / \mathrm{v})$ polymer solution in chloroform was prepared to fabricate polymer minitubes with an inner diameter of $2.8 \mathrm{~mm}$ by dip-coating of stainless steel mandrels. The dip-coating procedure was performed in a repetitive, automated dipping process until a nominal wall thickness of $300 \mu \mathrm{m}$ of the polymer tubes was achieved. The polymer tubes were then removed from the mandrels and washed in methanol and water for $24 \mathrm{~h}$ each to remove all solvent remnants.

In a second step, the polymer tubes were laser machined with a $\mathrm{CO}_{2}$ laser plotter (LP 1007, Wild Emco Lasertec, Hallein, Austria) to produce peripheral balloon-expandable slotted tube stent prototypes with nominal dimensions of $6.0 \times 25 \mathrm{~mm}$. The design pattern used for laser cutting has been reported on earlier by our group. ${ }^{8}$ Figure 1 shows a sample stent prototype.

\section{Mechanical and Thermal Analysis}

Mechanical properties of the tubular blanks were assessed at $37^{\circ} \mathrm{C}$ in uniaxial tensile tests with a ZWICKI ZN 2.5 (Zwick, Ulm, Germany). The gauge 


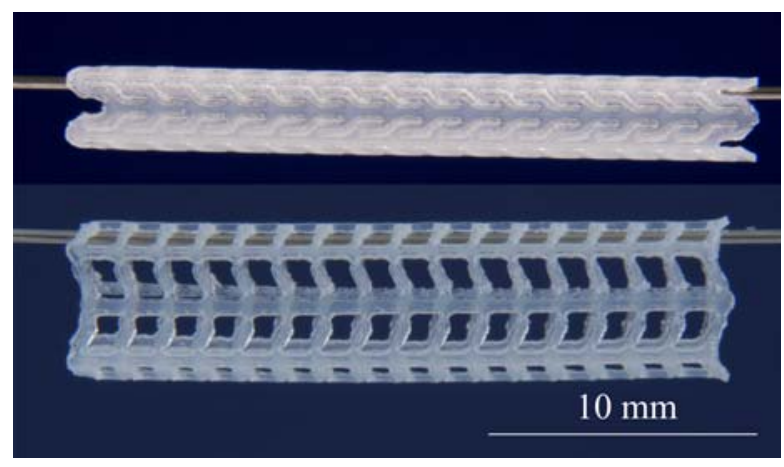

FIGURE 1. Balloon-expandable slotted tube PLLA/P4HB stent prototype in the unexpanded (top) and expanded state (bottom). Comparison of the two states illustrates the small stent foreshortening of $<3 \%$.

length and crosshead speed were $20 \mathrm{~mm}$ and $40 \mathrm{~mm} /$ min, respectively.

Thermo-mechanical analysis was carried out on a Dynamic Mechanical Analyzer DMA 2980 (TAInstruments, New Castle, Delaware, USA). The specimens were cooled and equilibrated at a temperature of $-80{ }^{\circ} \mathrm{C}$ using a nitrogen gas cooling unit. Then temperature was ramped at a heating rate of $2{ }^{\circ} \mathrm{C} / \mathrm{min}$ up to $120^{\circ} \mathrm{C}$. During heating, the specimens were oscillated with an amplitude of $25 \mu \mathrm{m}$ at a frequency of $1 \mathrm{~Hz}$.

Melting behavior was measured by differential scanning calorimetry (DSC) on a Mettler-Toledo Thermosystem FP900 with a DTA/DSC-sensor FP84 (Mettler-Toledo, Schwerzenbach, Switzerland). The heating rate was $5{ }^{\circ} \mathrm{C} / \mathrm{min}$. Degree of crystallinity was determined separately for the P4HB and PLLA phase of the blend, based on the specific heat of fusion known for $100 \%$ cystalline PLLA $(93.7 \mathrm{~J} / \mathrm{g})^{7}$ and P4HB $(76 \mathrm{~J} / \mathrm{g}){ }^{18}$

\section{Stent Bench Testing}

The stents were mounted on standard $6.0 \times 30 \mathrm{~mm}$ balloon catheters (Pheron, Biotronik $\mathrm{GmbH} \& \mathrm{Co}$. KG, Berlin, Germany). Stent expansion was achieved within 1 min by steady balloon inflation at a rate of $8 \mathrm{bar} / \mathrm{min}$ to a balloon pressure of $8 \mathrm{bar}$. Prior to expansion, the stents were preconditioned in a $37{ }^{\circ} \mathrm{C}$ water bath for $5 \mathrm{~min}$. Expansion and recoil measurements were conducted in a dedicated test chamber, described in detail in. ${ }^{21}$ Briefly, the stent systems were installed in a $37^{\circ} \mathrm{C}$ water bath. A computer-controlled pump was used for balloon inflation. Stent profile during balloon inflation and stent recoil at balloon deflation were measured optically with a dual-axis laser measuring head (ODAC $32 \mathrm{XY}$, ZUMBACH Electronic AG, Orpund, Switzerland), and recorded with a PC.
Stent collapse was assessed after inserting dilated stent specimens into thin walled polyurethane tubes open to the ambient atmosphere. The stented tubes were then immersed in a $37^{\circ} \mathrm{C}$ water filled pressure chamber according to. ${ }^{21}$ The hydraulic pressure in the chamber was raised in steps of 0.05 bar at a rate of $0.5 \mathrm{bar} / \mathrm{min}$ by a computer controlled piston pump. Simultaneously, the stent diameter was monitored optically in two orthogonal directions with a dual-axis laser measuring head (ODAC $32 \mathrm{XY}$, ZUMBACH Electronic AG, Orpund, Switzerland), and recorded with a PC.

\section{Scanning Electron Microscopy}

Expanded stent specimens were prepared for detailed analysis of strut deformation and surface morphology, and viewed using a Philips XL 30 ESEM (Philips Electron Optics, The Netherlands) scanning electron microscope in SEM mode.

\section{In vitro Stent Degradation}

Expanded stent specimens were incubated in Sørensen buffer solution $(0.1 \mathrm{~mol} / \mathrm{l}, \mathrm{pH}=7.4)$ at $37^{\circ} \mathrm{C}$ to evaluate hydrolytic degradation in vitro. After $0 / 2 / 4 / 8 / 12 / 24 \mathrm{w}$, stent specimens were removed from storage and tested for their remaining collapse stability, as described in the collapse testing section. Pieces of collapsed stents were analyzed by gel permeation chromatography (GPC) to determine molecular weight. The molecular weight of stent material was plotted over $48 \mathrm{w}$.

The GPC system (Thermo Separation Products, San Jose, USA) utilized a Shodex RI 71 refractive index detector (Showa Denko K.K., Tokyo, Japan) and a viscosity detector $\eta$-1000 (WGE Dr. Bures GmbH \& Co KG, Dallgow, Germany). The system further contained three PSS (Polymer Standards Service GmbH, Mainz, Germany) SDV $10 \mu \mathrm{m}$ columns $\left(10^{3}\right.$, $10^{5}, 10^{6} \AA$ ) in series at $35^{\circ} \mathrm{C}$. Chloroform was used as solvent and eluant at a flow rate of $1 \mathrm{ml} / \mathrm{min}$. The sample concentration was $1.0 \mathrm{mg} / \mathrm{ml}$, and the injection volume was $100 \mu \mathrm{l}$. Results were obtained using the method of universal calibration, based on 12 narrow dispersed polystyrene standards (Polymer Standards Service GmbH, Mainz, Germany).

\section{Data Analysis}

Expansion, recoil, and collapse data were obtained on the basis of $n \geq 3$ specimens tested for each measurement. Degradation data are based on the testing of $n=3$ samples at each time point. Arithmetic mean and standard deviation of the mean values were 
calculated. Statistical analysis was conducted using the two-tailed $t$-test for independent samples with unequal variances. A $p$-level $<0.05$ was considered statistically significant.

\section{RESULTS}

\section{Mechanical and Thermal Analysis}

Comparison of the tensile properties of the PLLA/ P4HB blend with the cited PLLA tensile data illustrates, that the addition of $22 \%$ P4HB to PLLA lowers the elastic modulus and the tensile strength by approx. $52 \%$ and $20 \%$, respectively, see Table 1 . However, elongation to break increases approximately 16 -fold.

Dynamic thermo-mechanical analysis confirms the lowered modulus of the blended material (Fig. 2), and also shows that addition of $\mathrm{P} 4 \mathrm{HB}$ produces a second relaxation slope, as well as a shift of the glass transition range towards lower temperatures. Glass transition of the $\mathrm{P} 4 \mathrm{HB}$ phase in the blended material was observed at $-62{ }^{\circ} \mathrm{C}$ (onset of $\mathrm{E}^{\prime}$ ). The main relaxation of the blend was measured at $34{ }^{\circ} \mathrm{C}$ (onset of $\mathrm{E}^{\prime}$ ). Storage modulus $\mathrm{E}^{\prime}$ was $2.0 \mathrm{GPa}$ at $20^{\circ} \mathrm{C}$, and $1.5 \mathrm{GPa}$ at $37{ }^{\circ} \mathrm{C}$. Relaxation of the pure PLLA material was measured at $60{ }^{\circ} \mathrm{C}$ (onset of $\mathrm{E}^{\prime}$ ), with $\mathrm{E}^{\prime}$ being $3.2 \mathrm{GPa}$ $\left(20^{\circ} \mathrm{C}\right)$, and $3.1 \mathrm{GPa}\left(37^{\circ} \mathrm{C}\right)$.

TABLE 1. Tensile test material data of solution cast tubular PLLA/P4HB (22\% P4HB) specimens at $37^{\circ} \mathrm{C}$.

\begin{tabular}{lccc}
\hline & $\begin{array}{c}\text { Elastic modulus } \\
(\mathrm{GPa})\end{array}$ & $\begin{array}{c}\text { Tensile strength } \\
(\mathrm{MPa})\end{array}$ & $\begin{array}{c}\text { Elongation } \\
\text { at break (\%) }\end{array}$ \\
\hline PLLA/P4HB & $1.0 \pm 0.1$ & $36 \pm 3$ & $126 \pm 46$ \\
PLLA & $2.1 \pm 0.5$ & $45 \pm 2$ & $8 \pm 1$ \\
\hline
\end{tabular}

Data are mean values of 6 measurements \pm standard deviation. For comparative purposes, the PLLA/P4HB data are compared to PLLA data from Grabow et $a l^{8}$.

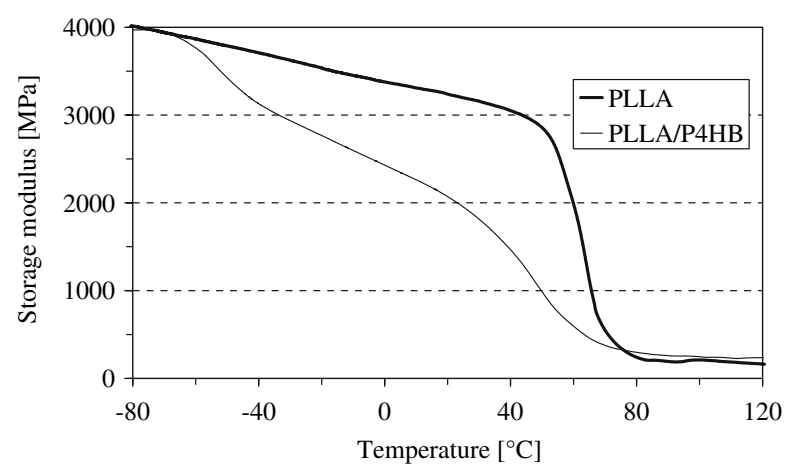

FIGURE 2. Modulus-temperature relationship for PLLA/ P4HB and pure PLLA.
The DSC data given in Table 2 indicate the marked reduction of crystallinity of the PLLA phase by approx. $49 \%$ in the blended material compared to the referenced crystallinity data for pure PLLA. Similarly, the crystallinity of the $\mathrm{P} 4 \mathrm{HB}$ phase in the blend was reduced by approx. $83 \%$ compared to earlier studies where we determined a crystallinity of $53 \%$ for similarly processed pure P4HB film samples (unpublished data). There was, however, no lowered melting temperature of PLLA in the blended material, see Table 2.

\section{Stent Expansion and Recoil}

The stent expansion protocol, preconditioning of the stents for $5 \mathrm{~min}$ at $37^{\circ} \mathrm{C}$ and subsequent ballooninflation to 8 bar in $1 \mathrm{~min}$, allowed for successful expansion of all tested stent specimens. All stents were expanded evenly with uniformly circular cross sections, and completely without the occurrence of strut ruptures. Figure 3 shows the stent expansion behavior during balloon pressurization and demonstrates that the PLLA/P4HB stents expand at balloon pressures between 1 and 2 bar and are fully expanded at nominal balloon pressure ( 6 bar). Figure 3 also indicates, that stent diameter can be further increased by overexpansion to 8 bar.

TABLE 2. Melting behavior and crystallinity of solution cast tubular PLLA/P4HB specimens.

\begin{tabular}{llcc}
\hline & $\begin{array}{c}\text { Melting peak } \\
\text { temperature }\left({ }^{\circ} \mathrm{C}\right)\end{array}$ & $\begin{array}{c}\text { Specific } \\
\text { enthalpy }(\mathrm{J} / \mathrm{g})\end{array}$ & $\begin{array}{c}\text { Degree of } \\
\text { crystallinity }(\%)\end{array}$ \\
\hline PLLA/P4HB & 60 (P4HB phase) & 7 & 9 \\
PLLA & 182 (PLLA phase) & 17 & 18 \\
& 182 & 33 & 35 \\
\hline
\end{tabular}

For comparative purposes, the PLLA/P4HB data are compared to PLLA data from Grabow et $a l^{10}$.

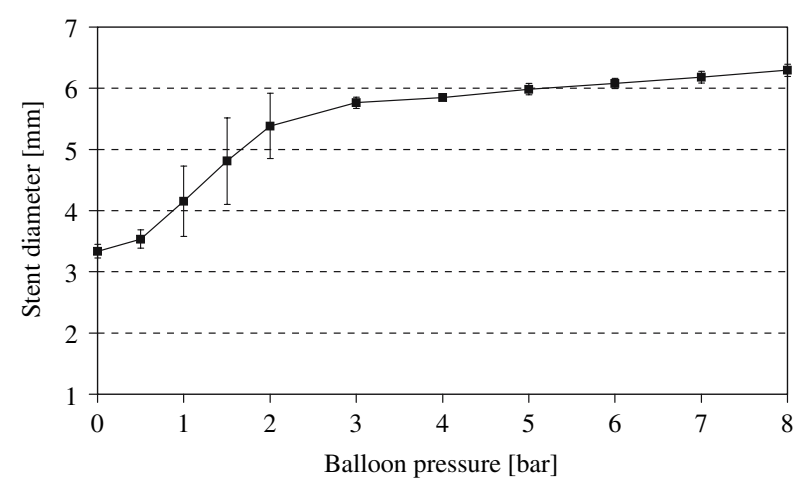

FIGURE 3. Stent pressure-diameter behavior during balloon expansion. The curve reflects the stent diameter measured in the stent midsection. 

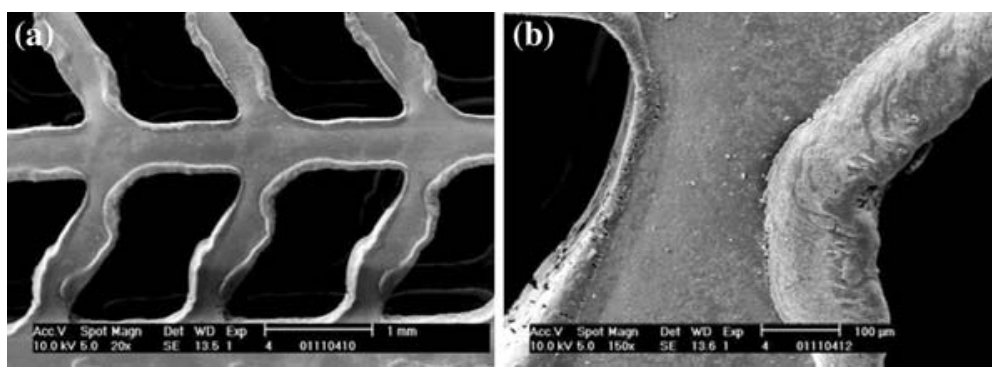

FIGURE 4. Electron micrographs of an expanded stent specimen at $20 \times$ (a) and $150 \times$ (b). The images show in detail the melted strut edges caused by the $\mathrm{CO}_{2}$ laser cutting and the integrity of the strut deformation zones after stent expansion.

The well tolerated overexpansion of the stent design is also demonstrated by the electron microscopical analysis. It can be seen in Fig. 4, that $\mathrm{CO}_{2}$ laser cutting causes melting of the strut edges, which may contribute to the prevention of crack initiation in the highly deformed outer strut regions.

The mean elastic recoil of the stents was $4.2 \pm 2.5 \%$, measured after deflation of the ballooncatheter from 8 bar.

\section{Stent Collapse}

Stent collapse measurements showed that external pressurization of the stents initially results in a uniform diameter reduction until just over 0.6 bar (see Fig. 5). Further increase of the external pressure subsequently leads to instability and induces buckling of the stent, resulting in a progressive ovalization of the cross section and ultimately stent collapse. Therefore, stent behavior under external pressure can be expressed in

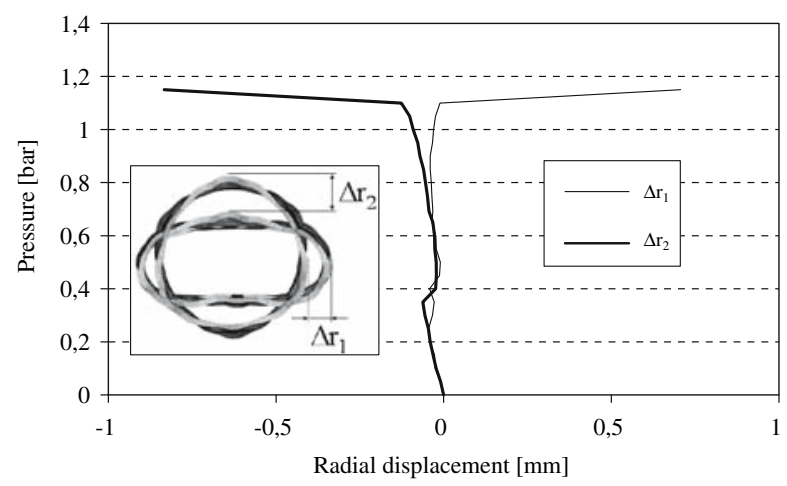

FIGURE 5. Representative radial displacement curves of a stent under increasing external pressure. The inset is composed of superimposed images from numerical analysis of stent collapse, showing axial views of the stent in the expanded and collapsed configuration. It illustrates the ovalization of the stent under external pressure, which can be expressed in terms of the radial displacement parameters $\Delta r_{1}$ and $\Delta r_{2}$. Between 0.2 and 0.4 bar the curves show a typical artifact of the measurement which is created when the increasing outer load initiates an evasive rotational movement of the stent in the laser scanning field. terms of the radial displacement parameters $\Delta r_{1}$ and $\Delta r_{2}$, as depicted in Fig. 5.

Figure 5 also shows the representative radial displacement curves of a PLLA/P4HB stent under external pressure. The curves illustrate the uniform diameter reduction of the stent up to a pressure of approximately 0.6 bar, which can be interpreted as radial compliance of the stent. Above this pressure, the two displacement curves $\Delta r_{1}$ and $\Delta r_{2}$ bifurcate, and the stent starts to ovalize. The abrupt splitting of the curves at a pressure of 1.1 bar is an indicator of stent collapse.

The mean collapse pressure measured for the stents was $1.1 \pm 0.25$ bar.

\section{In vitro Degradation}

In the first phase of incubation in Sørensen buffer solution $\left(\mathrm{pH}=7.4,37^{\circ} \mathrm{C}\right)$ for in vitro degradation, the stents exhibited an increase in collapse pressure. The maximum collapse pressures were obtained after 4 weeks, when the mean collapse pressure was $175 \%$ of the original value at the beginning of in vitro incubation. The collapse pressures subsequently decreased, but at 24 weeks they were still above the initial value, see Fig. 6.

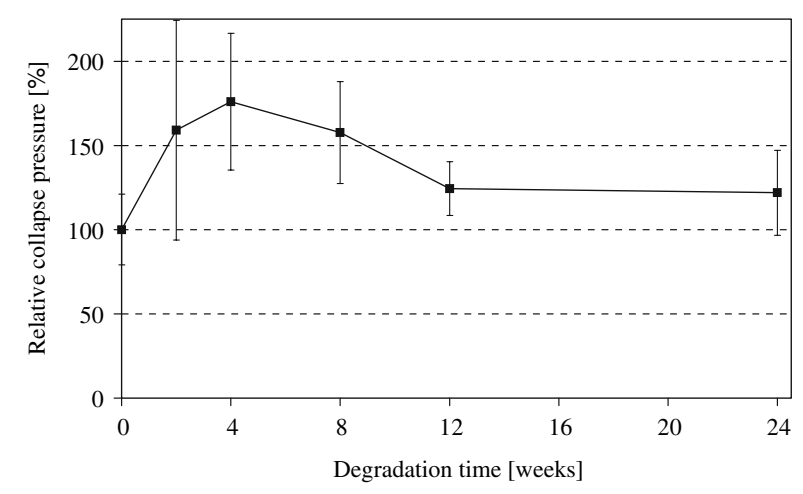

FIGURE 6. Stent collapse pressure as a function of incubation time in Sørensen buffer $(\mathrm{pH}=7.4)$ at $37^{\circ} \mathrm{C}$. 


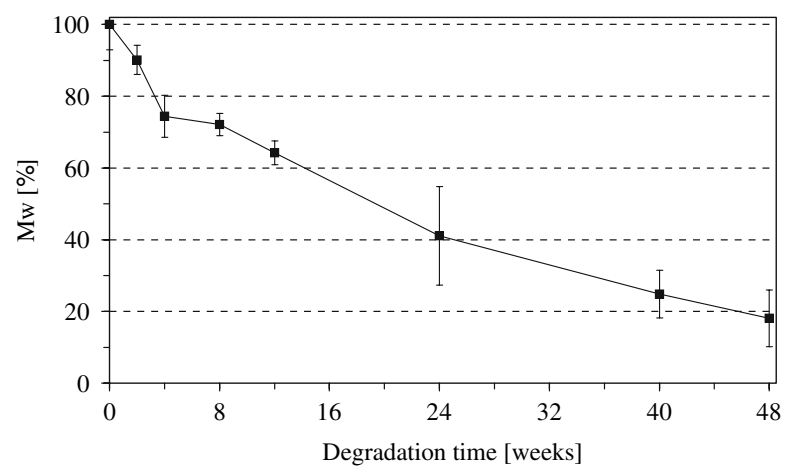

FIGURE 7. Molecular weight $M_{\mathrm{w}}$ as a function of incubation time in Sørensen buffer $(\mathrm{pH}=7.4)$ at $37^{\circ} \mathrm{C}$.

The GPC measurements showed a gradual and steady molecular weight decrease of the PLLA/P4HB blend material during the in vitro degradation study. The molecular weight at the beginning of in vitro incubation was determined as a single peak for the polymer blend with $M_{\mathrm{w}}=357,000 \mathrm{~g} / \mathrm{mol}$. After 48 weeks, the molecular weight of the blend material had decreased by $82 \%$ to approximately $64,000 \mathrm{~g} / \mathrm{mol}$, see Fig. 7. However, there was no mass loss apparent after this time.

\section{DISCUSSION}

Safe clinical application of a biodegradable polymeric stent requires rapid expansion, low recoil, and high collapse pressure of the stent. The results from the mechanical bench tests show that the presented stent fulfils these demands. The stent can be expanded at moderate balloon pressures, and even exhibits safety in application in overexpansion situations, which commonly occur in clinical practice to adjust stent sizing. ${ }^{5}$ The described preconditioning period of $5 \mathrm{~min}$ in $37^{\circ} \mathrm{C}$ water, however, does not actually fit in current clinical routines, and may need to be shortened.

Rapid stent expansion within $1 \mathrm{~min}$, compared to 8 min for our previous PLLA stent, was made possible by the blending of PLLA with P4HB. Although further mechanical testing, addressing the non-linear material behavior, may be necessary to fully understand the effects of $\mathrm{P} 4 \mathrm{HB}$ blending, the tensile tests and the thermo-mechanical analyses indicate, that this effect results from the increased ductility and lowered glass transition of the material.

The in vitro degradation tests show that the stents maintain their load bearing capacities for a time period of at least 24 weeks. The detected increase in collapse pressure can be attributed to recrystallization of the polymer material during in vitro incubation. We have also observed this with pure PLLA, ${ }^{8}$ and it has also been reported by Tan and Venkatraman et al., for PLGA. $^{24}$

The steady molecular weight decrease of the PLLA/ $\mathrm{P} 4 \mathrm{HB}$ blend material during the in vitro incubation period of 48 weeks is more pronounced than with pure high molecular weight PLLA, for which we have observed a reduction of molecular weight of $28 \%$ after $24 \mathrm{w},{ }^{8}$ and $55 \%$ after $48 \mathrm{w} .{ }^{9}$

Accelerated degradation of the PLLA/P4HB blend material can be attributed in part to the lower molecular weight P4HB blend component, the lowered glass transition and the lower degree of crystallinity of the polymer blend, as compared to pure PLLA. The blended material may also allow better water diffusion throughout the material and increase the rate of polymer hydrolysis.

Interestingly, the increase in stent collapse pressure during in vitro storage is progressing conversely to the observed decrease in molecular weight starting immediately after in vitro incubation. However, after 4 weeks of in vitro storage the progressive trend of the collapse pressure curves is reversed and follows the decline of molecular weight.

\section{CONCLUSIONS}

The low recoil, high collapse pressure and rapid balloon-expandability of the slotted-tube PLLA/P4HB stent described herein provide adequate mechanical characteristics for a broad range of peripheral vascular and non-vascular applications. In particular recoil $(4.2 \%)$ and collapse pressure (1.1 bar) are comparable to those of commercial peripheral metallic stents, for which recoil values of $2.5-4.8 \%$, and collapse pressures of $0.8-1.2$ bar are known. ${ }^{20}$ These characteristics were achieved with a strut thickness of $300 \mu \mathrm{m}$, which compares to a range of $160-220 \mu \mathrm{m}$ for current peripheral $6.0 \mathrm{~mm}$ balloon-expandable metallic stents. ${ }^{11}$

However, the key feature of the stent concept presented here is the fact that the PLLA/P4HB polymeric blend material provides a stent with both, load bearing capacity and the capability for rapid expansion, at the same time.

This is a pivotal advantage over our previous technology based solely on PLLA, and may ultimately permit the development of a coronary stent concept. Other vascular applications in reach are the treatment of renal, iliac or femoral artery stenoses, and stenoses of prosthetic arteriovenous grafts. Potential non-vascular applications may be, for instance, the treatment of urethral or biliary tract stenoses.

Important issues that will have to be addressed during further stent development are long-term deg- 
radation behavior ( $>1$ year), fatigue testing under dynamic conditions, and the identification of appropriate sterilization protocols and options for drug incorporation. The in vivo performance and degradation of the stent will also need to be evaluated. Recently the PLLA/P4HB stent has been successfully used by our group as an anastomotic support stent in the porcine iliac artery. Stent patency and integrity was maintained during the follow-up period of $6 \mathrm{w} .^{3}$

\section{ACKNOWLEDGMENTS}

The authors wish to express their appreciation to Dipl.-Ing. Peter Behrens and Dr.-Ing. Wolfram Schmidt, Institute for Biomedical Engineering, University of Rostock, for sharing their expertise in stent testing. Dipl.-Ing. Steffen Mews, Institute for Biomedical Engineering, University of Rostock, is gratefully acknowledged for his technical support during the stent degradation study.

\section{REFERENCES}

\footnotetext{
${ }^{1}$ Anderson, H. V., P. P. Leimgruber, G. S. Roubin, D. L. Nelson, and A. R. Gruentzig. Distal coronary artery perfusion during percutaneous transluminal coronary angioplasty. Am. Heart J. 110:720-726, 1985.

${ }^{2}$ Biamino, G. Biodegradable stents in the sfa: are they the answer? International Symposium on Endovascular Therapy 2006.

${ }^{3}$ Bünger, C. M., N. Grabow, K. Sternberg, M. Goosmann, K. P. Schmitz, H. J. Kreutzer, H. Ince, S. Klische, C. A. Nienaber, D. P. Martin, S. F. Williams, E. Klar, and W. Schareck. A biodegradable stent based on poly(L-lactide) and poly(4-hydroxybutyrate) for peripheral vascular application: preliminary experience in the pig. J. Endovasc. Ther. to appear October 2007.

${ }^{4}$ Bünger, C. M., N. Grabow, K. Sternberg, L. Ketner, C. Kröger, B. Lorenzen, K. Hauenstein, K. P. Schmitz, H. J. Kreutzer, D. Lootz, H. Ince, C. A. Nienaber, E. Klar, and W. Schareck. Iliac anastomotic stenting with a biodegradable poly-L-lactide stent: A preliminary study after 1 and 6 weeks. J. Endovasc. Ther. 13:539-548, 2006.

${ }^{5}$ Colombo, A., P. Hall, S. Nakamura, Y. Almagor, L. Maiello, G. Martini, A. Gaglione, S. L. Goldberg, and J. M. Tobis. Intracoronary stenting without anticoagulation accomplished with intravascular ultrasound guidance. Circulation 91:1676-1688, 1995.

${ }^{6}$ Erne, P., M. Schier, and T. J. Resink. The road to bioabsorbable stents: reaching clinical reality? Cardiovasc. Inter. Rad. 29:11-16, 2005.

${ }^{7}$ Fischer, E. W., H. J. Sterzel, and G. Wegner. Investigation of the structure of solution grown crystals of lactide copolymers by means of chemical reactions. Kolloid.-Z Z. Polym. 251:980-990, 1973.
}

${ }^{8}$ Grabow, N., C. Bunger, K. Sternberg, S. Mews, K. Schmohl, and K. P. Schmitz. Mechanical properties of a biodegradable balloon-expandable stent from poly(L-lactide) for peripheral vascular applications. $A S M E J$. Med. Dev. 1:84-88, 2007.

${ }^{9}$ Grabow, N., S. Mews, K. Schmohl, K. Sternberg, C. M. Bünger, and K. P. Schmitz. Long-term in vitro degradation study for a biodegradable PLLA stent. Biomaterialien (München) 7:154, 2006.

${ }^{10}$ Grabow, N., M. Schlun, K. Sternberg, N. Hakansson, S. Kramer, and K. P. Schmitz. Mechanical properties of laser cut poly(L-lactide) micro-specimens: Implications for stent design, manufacture, and sterilization. ASME J. Biomech. Eng. 127:25-31, 2005.

${ }^{11}$ Herzog, C., C. Grebe, A. Mahnken, J. O. Balzer, M. G. Mack, S. Zangos, H. Ackermann, S. Schaller, T. Seifert, B. Ohnesorge, and T. J. Vogl. Peripheral artery stent visualization and in-stent stenosis analysis in 16-row computed tomography: An in-vitro evaluation. Eur. Radiol. 15:22762283, 2005.

${ }^{12}$ Holmes, D. R. Jr., J. W. Moses, J. Schofer, M. C. Morice, E. Schampaert, and M. B. Leon. Cause of death with bare metal and sirolimus-eluting stents. Eur. Heart J. 27:28152822, 2006.

${ }^{13}$ Isotalo, T. M., J. P. Nuutine, A. Vaajanen, P. M. Martikainen, M. Laurila, P. Tormala, M. Talja, and T. L. Tammela. Biocompatibility properties of a new braided biodegradable urethral stent: a comparison with a biodegradable spiral and a braided metallic stent in the rabbit urethra. BJU Int. 97:856-859, 2006.

${ }^{14}$ Isotalo, T., M. Talja, T. Valimaa, P. Tormala, and T. L. Tammela. A bioabsorbable self-expandable, self-reinforced poly-L-lactic acid urethral stent for recurrent urethral strictures: long-term results. J. Endourol. 16:759-762, 2002.

${ }^{15}$ Joner, M., A. V. Finn, A. Farb, E. K. Mont, F. D. Kolodgie, E. Ladich, R. Kutys, K. Skorija, H. K. Gold, and R. Virmani. Pathology of drug-eluting stents in humans: delayed healing and late thrombotic risk. J. Am. Coll. Cardiol. 48:193-202, 2006.

${ }^{16}$ Lauto, A., M. Ohebshalom, M. Esposito, J. Mingin, P. S. Li, D. Felsen, M. Goldstein, and D. P. Poppas. Selfexpandable chitosan stent: design and preparation. Biomaterials 22:1869-1874, 2001.

${ }^{17}$ Martin, D. P., and D. F. Williams. Medical applications of poly-4-hydroxybutyrate: a strong flexible absorbable material. Biochem. Eng. J. 16:97-105, 2003.

${ }^{18}$ Mitomo, H., W. C. Hsieh, K. Nishiwaki, K. Kasuya, and Y. Doi. Poly(3-hydroxybutyrate-co-4-hydroxybutyrate) produced by comamonas acidovorans. Polymer 42:34553461, 2001.

${ }^{19}$ Ormiston, J. A., M. W. Webster, and G. Armstrong. Firstin-human implantation of a fully bioabsorbable drugeluting stent: the BVS poly-L-lactic acid everolimus-eluting coronary stent. Catheter. Cardiovasc. Interv. 69:128-131, 2006.

${ }^{20}$ Schmidt, W., R. Andresen, P. Behrens, and K. P. Schmitz. Characteristic mechanical properties of balloon-expandable peripheral stent systems. Rofo 174:1430-1437, 2002.

${ }^{21}$ Schmidt, W., and K. P. Schmitz. Devices. In: Mastering of Endovascular Techniques - A Guide to Excellence, edited by P. Lanzer. Philadelphia: Lippincott Williams \& Wilkins, 2006, pp. 114-135.

${ }^{22} \mathrm{Su}, \mathrm{S} . \mathrm{H} ., \mathrm{R}$. Y. Chao, C. L. Landau, K. D. Nelson, R. B. Timmons, R. S. Meidell, and R. C. Eberhart. Expandable 
bioresorbable endovascular stent. I. Fabrication and properties. Ann. Biomed. Eng. 31:667-677, 2003.

${ }^{23}$ Tamai, H., K. Igaki, E. Kyo, K. Kosuga, A. Kawashima, S. Matsui, H. Komori, T. Tsuji, S. Motohara, and $\mathrm{H}$. Uehata. Initial and 6-month results of biodegradable polyL-lactic acid coronary stents in humans. Circulation 102:399-404, 2000.

${ }^{24}$ Tan, L. P., S. S. Venkatraman, J. F. Joso, and F. Y. Boey. Collapse pressures of bilayered biodegradable stents. J. Biomed. Mater. Res. B Appl. Biomater. 79:102-107, 2006.

${ }^{25}$ Tanimoto, S., P. W. Serruys, L. Thuesen, D. Dudek, B. de Bruyne, B. Chevalier, and J. A. Ormiston. Comparison of in vivo acute stent recoil between the bioabsorbable everolimus-eluting coronary stent and the everolimus-eluting cobalt chromium coronary stent: insights from the ABSORB and SPIRIT trials. Catheter. Cardiovasc. Interv. 2007.
${ }^{26}$ Uurto, I., J. Mikkonen, J. Parkkinen, L. Keski-Nisula, T. Nevalainen, M. Kellomaki, P. Tormala, and J. P. Salenius. Drug-eluting biodegradable poly-D/L-lactic acid vascular stents: an experimental pilot study. J. Endovasc. Ther. 12:371-379, 2005.

${ }^{27}$ Venkatraman, S. S., L. P. Tan, J. F. Joso, Y. C. Boey, and $\mathrm{X}$. Wang. Biodegradable stents with elastic memory. Biomaterials 27:1573-1578, 2006.

${ }^{28}$ Vogt, F., A. Stein, G. Rettemeier, N. Krott, R. Hoffmann, J. vom Dahl, A. K. Bosserhoff, W. Michaeli, P. Hanrath, C. Weber, and R. Blindt. Long-term assessment of a novel biodegradable paclitaxel-eluting coronary polylactide stent. Eur. Heart J. 25:1330-1340, 2004.

${ }^{29}$ Zilberman, M., and R. C. Eberhart. Drug-eluting bioresorbable stents for various applications. Annu. Rev. Biomed. Eng. 8:153-180, 2006. 